\title{
Qualifying for The Quality Health Care for Children
}

\section{Sharma PR}

Department of Child Health

Kathmandu Medical College, Kathmandu, Nepal

Child health, as defined by Health Workgroup, is a state of physical, mental, intellectual, social and emotional well-being and not merely the absence of disease or infirmity. Healthy children live in families, environments, and communities that provide them with the opportunity to reach their fullest developmental potential. ${ }^{1}$ The role of family in providing quality health care cannot be ignored. ${ }^{2}$ Considering this definition from the perspective of quality of child health care, a disparity between the desired and existing level of child health services and outcomes commensurate with the current professional knowledge are evident. ${ }^{3}$ However, it is often difficult to measure these outcomes in children because of various reasons. ${ }^{4}$ Some drugs such as cough and cold preparations are freely available over the counter without medical prescription. Also, quality of care often cannot be validly measured or compared between different health care providers as the services provided for a specific problem varies tremendously. It is not uncommon for us to see excessive investigation and medication for a specific problem by health professionals in order to ward off any possible legal problem in future. Adolescents have a different perspective on their health and health care than either parents or treating pediatricians, yet his or her perspective is often ignored, both in practice and in research, which may lead to biased information. The desired outcomes are not measured by the parents or patients but by professional bodies who rely on the available recent scientific evidences.

Family and environment cannot be separated when we observe the child health and hence any program implemented for child health must be a part of family health. This is difficult as private and nongovernmental health care providers are more frequently consulted than those in the public sector for diseases that commonly affect children. In India, more than $90 \%$ of children affected by diarrhea are taken to private health care providers. In Nepal, more than $50 \%$ of children suffering from diarrhea and acute respiratory infections (ARI) are treated outside the public sector. ${ }^{5}$ The private health care set ups are not uniformly standardized in developing countries like ours. Also, standards of health care, especially in pediatrics vary between countries and hence it is difficult to compare the outcome of the services provided as valid comparisons. It is also challenging to measure success in achieving optimal child care due to continually growing physical and mental status of the pediatric population.

There are three perspectives that need to be looked deeply when we are talking about quality of care for children. The first and the foremost is evidence based health services at different levels, second is appropriate training of health professionals and third is the mode of payment for the services provided for child health.

The neglect of public sector hospitals by the Government has led to totally inadequate and inefficient health services to the pediatric population of this country. This will continue to grow unless special attention is given to bring quality child health care with quality health care professionals. At the same time, the cost of child health care from the private sector is way to high for an ordinary citizen without necessarily assuring the quality of care. Out-of-pocket expenditure on health, as a proportion of household expenditure, has increased with time in rural and urban areas. ${ }^{6}$ For Nepal it is estimated that the out of pocket expenditure for health care is $70-75 \%$ of the total health care expenditure. ${ }^{7}$ Expenditures on inpatient as well as outpatient health care are consistently higher in private facilities than in public facilities; and expenditure is greater for non-communicable diseases than for communicable diseases. ${ }^{8}$ Notably, the proportion of money spent on health has increased most for the poorest households. This raises the question of equity of health care for children: intra-family and intra-society.

Passive learning in medical education is rarely effective in changing outcomes. To this end, Kathmandu University has recently changed it's curriculum from passive learning to problem based learning which will hopefully produce quality health care professionals by incorporating quality improvement skills as a core competency; interactive skills training that permits "skills rehearsals"; and decision support tools and computerized prompts to help clinicians apply evidence. The available medical scientific gadgets, the electronic manikins, simulated patients and essential life saving skill courses are some examples that a postgraduate should be exposed to before graduating as pediatrician. 
In summary, provision of the quality health care for children of Nepal needs to be evaluated. It should be done in terms of availability, affordability and appropriateness. Appropriate provision should be made to measure the quality of health care by public and private sectors. In this connection the theme set by Nepalese Congress of Pediatrics "Challenges in Quality of Health Care in Children" for 2012 Congress seems certainly appropriate and will certainly help explore ways and means of improving child health care in Nepal both in terms of preventive as well as curative services.

\section{REFERENCES}

1. First Things First. Ready for school set for life. October, 2007: Available from: http://www.azftf.gov/ Recommendation.pdf.

2. American Academy of Pediatrics. Policy Statement: Patient- and Family-Centered Care and the Pediatrician's Role. Pediatrics 2012 Feb;129(2):394 -404.(doi: 10.1542/peds.2011-3084) Published online January 30, 2012.

3. Agency for Healthcare Research and Quality [Internet]. Rockville, MD: Child Health Care Quality Toolbox: Understanding Quality Measurement. July 2004. Available from http://www.ahrq.gov/chtoolbx/understn.htm

4. Houweling TA, Kunst AE, MackembachJP. Measuring health inequality among children in developing countries: does the choice of the indicator of economic status matter? Int J for equity in health. 2003;2:8

5. Bustero F, Harding A, Axelsson H. Can developing countries achieve adequate improvements in child health outcomes without engaging the private sector? Bulletin of the World Health Organization. 2003;81(12).

6. Y Balarajan, SSelvaraj, SV Subramanian. India: towards universal health coverage; health care and equity in India. Lancet 2011;377:50515. [Published on line Jan 12, 2011. DOI: 10.1016/S0140-6376 (10)61894-6.]

7. World Health Organization National Health Account database. Available from www.who.int/nha/en.

8. Mahal A, Karan A, Engelgau M. The Economic Implications of Non-Communicable Diseases for India. Paper prepared for World Bank, Washington, DC, USA, August 2009. 